\title{
Potential therapeutic value of medications in Mexico: the case of antibiotics
}

\author{
Dolores Mino-León, ${ }^{1}$ Ixzel Hernández-Carvajal, ${ }^{2}$ Luis Peredo-Silva ${ }^{3}$ and Gabriel Búrbano-Martínez ${ }^{4}$
}

${ }^{1}$ Instituto Mexicano del Seguro Social, Centro Médico Nacional Siglo XXI, Specialty Hospital, Clinical Epidemiology Research Unit, Ciudad de México; ${ }^{2}$ Universidad Autónoma de Morelos, Cuernavaca, Morelos; ${ }^{3}$ Universidad Nacional Autónoma de México, Faculty of Medicine, Ciudad de México; ${ }^{4}$ Independent researcher, Mexico

\begin{abstract}
Introduction: The relevance of medications for health depends on their quality, accessibility and appropriate use. Objective: To determine the potential therapeutic value of antibiotics that are not included in the World Health Organization Essential Medicines List (EML) but that are part of the National Essential Medicines List (NEML) of the Mexican Ministry of Health, and categorize them according to their intrinsic value. Method: Descriptive analysis of antibiotics not included in the 2013 World Health Organization EML; literature review to obtain efficacy and safety evidence; and application of quality and intrinsic value scales. Results: Four hundred and fifty-two abstracts were identified for 19 antibiotics; $56.9 \%$ were excluded; 195 clinical trials were reviewed in full-text articles, out of which $37.9 \%$ were of good quality, and intrinsic value was determined; $54 \%$ were superiority studies, whereas $46 \%$ were non-inferiority or equivalence studies; $32 \%$ of the antibiotics were classified without intrinsic value and nearly $50 \%$ were inconclusive. Conclusion: An elevated proportion of antibiotics of the NEML had uncertain or no intrinsic value, which favors their inappropriate use, bacterial resistance and puts the population at risk.
\end{abstract}

KEY WORDS: Antibiotics. Therapeutic value. Essential Medicines List. National Essential Medicines List.

\section{Introduction}

The relevance of medications for the health of a population depends on their quality, accessibility and correct use. Globally, half of them are inadequately prescribed, dispensed and consumed. ${ }^{1}$ The World Health Organization (WHO) promotes rational use of medications and recommends the inclusion of national drug policies, ${ }^{2}$ since once a drug is marketed it takes several years for it to be replaced or to exit the market when an unfavorable benefit/risk ratio is demonstrated. ${ }^{3-5}$

Antimicrobials annual market amounts 960 million dollars, it occupies the second place in sales and 950 million doses are consumed. Indiscriminate purchase and use of this type of medications has favored antimicrobial resistance. ${ }^{6}$ In North America, 23,000 deaths/ year have been reported for resistant infections. ${ }^{7}$
Antimicrobial resistance causes for an antibiotic to lose efficiency, become obsolete and be withdrawn from the market. ${ }^{8}$

The WHO developed an essential medicines list (EML) to meet disease global burden. In Mexico there are numerous drugs with an unfavorable risk/benefit balance. ${ }^{5,9}$ The National Essential Medicines List (NEML) includes antibiotics that are not in the WHO $E M L$, and it is therefore important updating it and evaluating the need to withdraw obsolete drugs or those with no or doubtful risk/benefit ratio and inadequate cost. ${ }^{10}$ Categorizing drugs according to their potential therapeutic value or "intrinsic value" (IV) has been proposed, based on the analysis of their therapeutic quality. ${ }^{10}$ The review of scientific evidence that at the time of marketing corresponds to clinical trials (CTs) has been used, and the Jadad scale has been employed to evaluate their methodological quality. ${ }^{11}$ 
Table 1. Clinical trials where antibiotics used in Mexico are analyzed according to their therapeutic group

\begin{tabular}{|c|c|c|c|c|c|c|c|c|c|c|c|}
\hline \multirow[t]{2}{*}{ Group } & \multirow{2}{*}{$\begin{array}{c}\begin{array}{c}\text { CTs } \\
(n=195)\end{array} \\
n\end{array}$} & \multicolumn{2}{|c|}{$\begin{array}{c}\text { Jadad } \geq 3 \\
(n=74)\end{array}$} & \multicolumn{2}{|c|}{$\begin{array}{l}\text { Superiority } \\
\qquad(n=40)\end{array}$} & \multicolumn{2}{|c|}{$\begin{array}{l}\text { Superiority, } \\
\text { PI-related } \\
(\mathbf{n = 2 6 )}\end{array}$} & \multicolumn{2}{|c|}{$\begin{array}{l}\text { Equivalence/Non } \\
\text { inferiority }(n=34)\end{array}$} & \multicolumn{2}{|c|}{$\begin{array}{c}\text { Equivalence/ } \\
\text { Non inferiority, } \\
\text { PI-related }(n=32)\end{array}$} \\
\hline & & $\mathrm{n}$ & $\%$ & $\mathrm{n}$ & $\%$ & $\mathrm{n}$ & $\%$ & $\mathbf{n}$ & $\%$ & $\mathbf{n}$ & $\%$ \\
\hline Beta-lactams & 56 & 27 & 36.5 & 12 & 30 & 9 & 34.6 & 15 & 44.1 & 15 & 46.9 \\
\hline Cephalosporins & 34 & 6 & 8.1 & 2 & 5 & 2 & 7.7 & 4 & 11.8 & 4 & 12.5 \\
\hline Macrolides & 11 & 2 & 2.7 & 2 & 5 & 2 & 7.7 & 0 & 0 & 0 & 0 \\
\hline Aminoglycosides & 18 & 11 & 14.9 & 8 & 20 & 3 & 11.5 & 3 & 8.8 & 2 & 6.2 \\
\hline Tetracyclines & 13 & 2 & 2.7 & 2 & 5 & 1 & 3.8 & 0 & 0 & 0 & 0 \\
\hline Others & 63 & 26 & 35.1 & 14 & 35 & 9 & 34.6 & 12 & 35.3 & 11 & 34.4 \\
\hline
\end{tabular}

$\mathrm{CT}=$ clinical trial, $\mathrm{PI}=$ pharmaceutical industry.

Owing to the impact of antibiotics on public health, it is important to determine the potential therapeutic value of those that are not included in the WHO EML, but do appear in the Ministry of Health of Mexico NEML and categorize them according to their IV.

\section{Method}

The 2013 WHO EML was the reference for antibiotics that should be included in the Ministry of Health NEML (2014). Antibiotics not included in the WHO EML were analyzed and assigned an IV. The Medline (PubMed) and Cochrane databases were reviewed from January 1984 to December 2014. CTs written in English and Spanish were included with the key term "randomized controlled trials" combined with the antibiotic generic name. Abstracts had to include the words "efficacy and/or safety" and the indication had to be "local and/or systemic infection". Those with indications for dental prophylaxis, topical use, Helicobacter pylori eradication, any indication other than infection and those where obtaining the full-length document was not possible were eliminated.

The CTs were applied the Jadad criteria; those that scored $\geq 3$ went on to the next stage. The researchers, both individually and by groups, reviewed the CTs in order to categorize the antibiotics according to their IV:

- High, drugs with efficacy demonstrated in CTs or whose efficacy has not been demonstrated in CTs, but whose use is justified in defined indications because they have immediate and obvious effects.

- Relative, irrational medications from a pharmacological and therapeutic point of view because, in addition to containing an active ingredient of high potential value, they contain one or more chemical components with uncertain therapeutic efficacy, whose addition to the preparation is not supported by any clinical data obtained in controlled conditions.

- Uncertain, drugs where there is controversy in the international literature regarding their longterm efficacy.

- No IV, drugs whose efficacy has not been convincingly demonstrated in CTs, but without a description of serious or frequent undesirable effects.

- Unacceptable, medications that owing to their composition show a clearly unfavorable risk/benefit ratio in all circumstances.

The participation of the pharmaceutical industry and the objective of the CTs (superiority, non-inferiority or equivalence) was registered. A descriptive analysis was carried out.

\section{Results}

Nineteen antibiotics were analyzed, with 452 abstracts being identified, out of which 257 were eliminated. One-hundred and ninety-five full-length articles were retrieved and applied the Jadad scale; only 74 (37.9 \%) with a score $\geq 3$ were included; $54 \%$ assessed superiority and $46 \%$ analyzed non-inferiority or equivalence. A total of $65 \%$ of superiority trials and $94.1 \%$ of non-inferiority or equivalence trials reported a relationship with the pharmaceutical industry.

The highest percentage of included CTs were about beta-lactams $(36.5 \%)$. All CTs on macrolides and tetracyclines were intended to demonstrate superiority, while the highest proportion of CTs on beta-lactams and others were intended to assess equivalence or non-inferiority. Regarding the participation of the pharmaceutical industry, a higher participation in CTs on beta-lactams, cephalosporins and others was observed (Table 1). 
Table 2. Clinical trials where beta-lactams used in Mexico are analyzed

\begin{tabular}{|c|c|c|c|c|c|}
\hline Name & Author & Year & Quality* & Objective ${ }^{* *}$ & $\mathrm{PI}^{* \star *}$ \\
\hline \multicolumn{6}{|c|}{ Piperacyclin/tazobactam } \\
\hline & Tan JS, et al. & 1993 & 4 & $S^{*}$ & No \\
\hline & Siami GA, et al. & 2001 & 4 & S & Yes \\
\hline & Siami FS, et al. & 2002 & 3 & S & Yes \\
\hline & Naber KG, et al. & 2002 & 3 & $\mathrm{Nl}^{*}$ & Yes \\
\hline & Cornely OA, et al. & 2004 & 3 & $\mathrm{NI}$ & Yes \\
\hline & Joshi M, et al. & 2006 & 4 & $S$ & Yes \\
\hline & Schmitt DV, et al. & 2006 & 3 & S & Yes \\
\hline & Yamamoto Y, et al. & 2013 & 3 & S & No \\
\hline \multicolumn{6}{|c|}{ Meropenem } \\
\hline & Feld $\mathrm{R}$, et al. & 2000 & 5 & S & Yes \\
\hline & Fabian TC, et al. & 2005 & 4 & $\mathrm{NI}$ & Yes \\
\hline & Lucasti C, et al. & 2013 & 5 & $S$ & Yes \\
\hline \multicolumn{6}{|c|}{ Ertapenem } \\
\hline & Tomera KM, et al. & 2002 & 5 & $E^{*}$ & Yes \\
\hline & Ortiz-Ruiz G, et al. & 2002 & 4 & $E$ & Yes \\
\hline & Graham D, et al. & 2002 & 3 & E & Yes \\
\hline & Jiménez-Cruz F, et al.. & 2002 & 3 & E & Yes \\
\hline & Vetter N, et al. & 2002 & 4 & E & Yes \\
\hline & Roy S, et al. & 2003 & 5 & E & Yes \\
\hline & Solomkin J, et al. & 2003 & 5 & $E$ & Yes \\
\hline & Barboza E, et al. & 2003 & 3 & $E$ & Yes \\
\hline & Gesser RM, et al. & 2004 & 5 & $S$ & Yes \\
\hline & Lipsky BA, et al. & 2005 & 5 & S & Yes \\
\hline & Itani K, et al. & 2006 & 5 & $\mathrm{NI}$ & Yes \\
\hline & Namias N, et al. & 2007 & 5 & $\mathrm{NI}$ & Yes \\
\hline & Arguedas A, et al. & 2009 & 3 & S & Yes \\
\hline & Park DW, et al. & 2012 & 4 & E & Yes \\
\hline & Catena F, et al. & 2013 & 4 & $S$ & No \\
\hline & Solomkin JS, et al. & 2014 & 4 & S & Yes \\
\hline
\end{tabular}

\section{Beta-lactams}

The piperacycline-tazobactam combination was not superior to the comparator and was classified with an uncertain IV. With meropenem, the results did not report superiority and was attributed a doubtful IV. No
Table 3. Clinical trials where cephalosporins and macrolides used in Mexico are analyzed

\begin{tabular}{|c|c|c|c|c|c|}
\hline Name & Author & Year & Quality* & Objective** & $\mathrm{PI}^{\star * *}$ \\
\hline \multicolumn{6}{|c|}{ Cefepime } \\
\hline & Raad II, et al. & 2003 & 3 & S & Yes \\
\hline & Yakovlev SV, et al. & 2006 & 5 & $\mathrm{NI}$ & Yes \\
\hline & Garbino J, et al. & 2007 & 5 & $\mathrm{NI}$ & Yes \\
\hline \multicolumn{6}{|c|}{ Cefuroxime } \\
\hline & Zervos MJ, et al. & 2003 & 4 & $S$ & Yes \\
\hline & UpChurch J, et al. & 2006 & 5 & $\mathrm{NI}$ & Yes \\
\hline & Álvarez-Sala JL, et al. & 2006 & 3 & $\mathrm{NI}$ & Yes \\
\hline \multicolumn{6}{|c|}{ Roxithromycin } \\
\hline & Ortqvist A, et al. & 1996 & 3 & S & Yes \\
\hline & Hopstaken RM, et al. & 2002 & 5 & S & No \\
\hline
\end{tabular}

*Jadad scale.

${ }^{*}$ Superiority (S), Non-inferiority (NI), Equivalence (E).

${ }^{* * *}$ Relationship with the pharmaceutical industry.

dicloxacillin CT met the quality criteria, and it was thus considered without IV. One ertapenem superiority CT confirmed it, but the rest reported equivalence, which is why it was attributed an uncertain IV (Table 2).

\section{Cephalosporins}

No CT with cefaclor, cephalothin and cefpirome had methodological quality, and thus they were classified as without IV. CTs with cefepime and cefuroxime revealed no inferiority and thus these drugs were classified as having an uncertain IV (Table 3).

\section{Macrolides}

Roxithromycin showed no superiority and thus it was classified as having an uncertain IV (Table 3 ).

\section{Aminoglycosides}

The indication for tobramycin in all CTs was pulmonary infection in patients with cystic fibrosis, where it demonstrated efficacy, which is why it was attributed a high IV; the same rating was given to neomycin (Table 4).

\section{Tetracyclines}

Minocycline did not outperform its comparators and made the treatment more expensive and thus it was 
Table 4. Clinical trials where aminoglycosides and tetracyclines used in Mexico are analyzed

\begin{tabular}{|c|c|c|c|c|c|}
\hline Name & Author & Year & Quality* & Objective ${ }^{* *}$ & $\mathrm{PI}^{* * *}$ \\
\hline \multicolumn{6}{|c|}{ Tobramycin } \\
\hline & Rodríguez JR, et al. & 1985 & 3 & S & Yes \\
\hline & Church DA, et al. & 1997 & 3 & E & Yes \\
\hline & Ramsey BW & 1999 & 3 & S & No \\
\hline & Bilton D, et al. & 2006 & 3 & S & Yes \\
\hline & Treggiari MM, et al. & 2011 & 5 & S & No \\
\hline & Trapnell BC, et al. & 2012 & 3 & S & No \\
\hline \multicolumn{6}{|c|}{ Neomycin } \\
\hline & van Balen FA, et al. & 2003 & 5 & S & No \\
\hline & Notivol R, et al. & 2004 & 5 & $\mathrm{NI}$ & No \\
\hline & Roland PS, et al. & 2008 & 4 & $\mathrm{NI}$ & Yes \\
\hline & Huttner B, et al. & 2013 & 5 & S & No \\
\hline & Pimentel M, et al. & 2014 & 4 & S & Yes \\
\hline \multicolumn{6}{|c|}{ Minocyclin } \\
\hline & Ozolins M, et al. & 2004 & 4 & S & No \\
\hline & Leyden J, et al. & 2006 & 3 & S & Yes \\
\hline
\end{tabular}

classified with an uncertain IV. CTs of oxytetracycline/ doxycycline and tetracycline were of no quality and thus these drugs were classified as "without IV" (Table 4).

\section{Others}

One quinupristin/dalfopristin CT showed similar efficacy than the comparator, but the comparator had a higher risk of causing thrombocytopenia, and thus the drug was assigned a high IV. The tigecycline CTs demonstrated that it is not inferior, and thus its IV was regarded as uncertain. In general, linezolid was not superior and was equivalent and non-inferior versus its comparator; it was attributed an uncertain IV. Teicoplanin was shown to be effective and to cause fewer side effects compared to vancomycin; it was granted a high IV (Table 5).

\section{Discussion}

The EML is based on the principle that "a careful selection of a limited number of drugs results in better quality of care, better usage and favors the most
Table 5. Clinical trials where the other antibiotics group is analyzed

\begin{tabular}{|c|c|c|c|c|c|}
\hline Name & Author & Year & Quality* & Objective $^{* *}$ & $\mathrm{PI}^{\star \star *}$ \\
\hline \multicolumn{6}{|c|}{ Quinupristin } \\
\hline & Raad I, et al. & 2004 & 3 & $S$ & No \\
\hline \multicolumn{6}{|c|}{ Tigecyclin } \\
\hline & Oliva ME, et al. & 2005 & 4 & $\mathrm{NI}$ & Yes \\
\hline & Breedt J, et al. & 2005 & 3 & $\mathrm{NI}$ & Yes \\
\hline & Fomin $\mathrm{P}$, et al. & 2005 & 5 & $\mathrm{NI}$ & Yes \\
\hline & Sacchidanand S, et al. & 2005 & 4 & $\mathrm{NI}$ & Yes \\
\hline & Florescu I, et al. & 2008 & 5 & S & Yes \\
\hline & Tanaseanu C, et al. & 2009 & 5 & $\mathrm{NI}$ & Yes \\
\hline & Bergallo $\mathrm{C}$, et al. & 2009 & 3 & $\mathrm{NI}$ & Yes \\
\hline & Freire AT, et al. & 2010 & 3 & $\mathrm{NI}$ & Yes \\
\hline \multicolumn{6}{|c|}{ Linezolid } \\
\hline & Stevens DL, et al. & 2000 & 4 & $S$ & Yes \\
\hline & Rubinstein E, et al. & 2001 & 3 & $E$ & Yes \\
\hline & Wunderink RG, et al. & 2003 & 3 & $S$ & Yes \\
\hline & Cepeda JA, et al. & 2004 & 4 & S & Yes \\
\hline & Jaksic B, et al. & 2006 & 4 & $E$ & Yes \\
\hline & Lin DF, et al. & 2008 & 3 & Pilot & Yes \\
\hline & Wunderink RG, et al. & 2012 & 5 & $\mathrm{NI}$ & Yes \\
\hline & Moran GJ, et al. & 2014 & 5 & $\mathrm{NI}$ & Yes \\
\hline
\end{tabular}

Teicoplanin

\begin{tabular}{lllll} 
Kureishi A, et al. & 1991 & 5 & S & Yes \\
Gilbert DN, et al. & 1991 & 5 & S & Yes \\
Chow AW, et al. & 1993 & 4 & S & No \\
Rolston KV, et al. & 1994 & 5 & S & No \\
Neville LO, et al. & 1995 & 3 & S & Yes \\
Liu CY, et al. & 1996 & 3 & S & Yes \\
Rolston KV, et al. & 1999 & 4 & E & No \\
Vazquez L, et al. & 1999 & 3 & S & No \\
D'Antonio D, et al. & 2004 & 3 & S & No \\
\hline \multirow{2}{*}{$\begin{array}{l}\text { Cale. } \\
\text { rity (S), non-inferiority (NI), equivalence (E). }\end{array}$} & &
\end{tabular}

efficient expenditure of resources". When developing an EML, the prevalence of diseases, scientific evidence and the cost-effectiveness ratio must be considered. ${ }^{12,13}$ The study results show a part of the problem in Mexico, since one third part of the antibiotics was classified without IV, which means that the 
population is exposed to unnecessary risk. The fact that $38 \%$ of CTs had satisfactory methodological quality draws the attention to one of the principles for selecting drugs: using the best evidence, ${ }^{13,14}$ and this is strengthened by the fact that almost half had an uncertain IV, i.e. insufficient evidence. The literature mentions that approximately $70 \%$ of drugs in the world market are non-essential, i.e. they do not offer any therapeutic advantage in relation to those available, and even have higher toxicity ${ }^{14}$ or increase the costs, ${ }^{15}$ as it occurred with minocycline.

\section{Conclusion}

The fact that a considerable proportion of antibiotics have an uncertain or no IV favors their inadequate use and the development of bacterial resistance, and puts the population at risk.

\section{References}

1. World Health Organization. The world medicines situation 2004. Ginebra, Suiza: World Health Organization; 2004.

2. World Health Organization. The rational use of drugs. Report of the conference of experts, Nairobi, 25-29 November 1985. Ginebra, Suiza: World Health Organization; 1987.
3. Hoyle M. Historical lifetimes of drugs in England: application to value of information and cost-effectiveness analyses. Value Health. 2010;13: 885-892.

4. Diogene E, Figueras A. What public policies have been more effective in promoting rational prescription of drugs? J Epidemiol Community Health. 2011;65:87-88.

5. Rico-Alba I, Figueras A. The fuzzy line between needs, coverage, and excess in the Mexican formulary list: an example of qualitative market width analysis. Eur J Clin Pharmacol. 2013;69:949-956.

6. Dreser A, Wirtz VJ, Corbett KK, Echániz G. Uso de antibióticos en México: revisión de problemas y políticas. Salud Publica Mex. 2008; 50:S480-S487.

7. Floyd JS, Psaty BM. The potential risks of expedited approval of drugs for acute bacterial infections. JAMA Intern Med. 2014;174:1436-1437.

8. López-Navas A, García-Escribano Ráez N, Flores-Juberías Á, SuárezGea ML. Procedure for the marketing authorization of an antibacterial agent. Enferm Infecc Microbiol Clin. 2014;32:529-532.

9. Rico-Alba I, Figueras A. The evolution of reference drug lists and clinical practice guidelines in the public health system of a middle-income country. Br J Clin Pharmacol. 2014;78:410-421.

10. Laporte JR, Porta M, Capella D. Drug utilization studies: a tool for determining the effectiveness of drug use. Br J Clin Pharmacol. 1983;16: 301-304.

11. Jadad AR, Moore RA, Carroll D, Jenkinson C, Reynolds DJ, Gavaghan DJ, et al. Assessing the quality of reports of randomized clinical trials: is blinding necessary? Control Clin Trials. 1996;17:1-12.

12. World Health Organization. Selection of essential medicines. Ginebra, Suiza: World Health Organization; 2016.

13. Perumal-Pillay VA, Suleman F. Selection of essential medicines for South Africa: an analysis of in-depth interviews with national essential medicines list committee members. BMC Health Serv Res. 2017;17:17.

14. Management Sciences for Health. MSD-3: Managing access to medicines and health technologies. EE. UU.: Management Sciences for Health; 2012.

15. Ozolins M, Eady EA, Avery AJ, Cunliffe WJ, Po AL, O'Neill C, et al. Comparison of five antimicrobial regimens for treatment of mild to moderate inflammatory facial acne vulgaris in the community: randomised controlled trial. Lancet. 2004;364:2188-2195. 